\section{ULTRASONOGRAPHY: farewell and introduction of the new Editor-in-Chief}

JEONG-SIK YU

Editor-in-Chief

ULTRASONOGRAPHY

The time has now come for me to wrap up my work as the Editor-in-Chief (EIC) of Ultrasonography and leave. Due to some unavoidable causal circumstances, a substantial component of the apprehension that I felt when I first took on the role of EIC for this journal was anxiety about how to solve the inherent problems of a domestic journal, which was losing popularity at the time, but my larger concern was that I doubted whether this work was worth putting my time and passion into. The most difficult thing for me in this position was experiencing moment-to-moment frustrations at the failure of various plans and results that did not meet expectations, which often resulted from differences in priorities and viewpoints between myself and others.

"If you can't stand the century after all, why are you overusing your spirit?" (from Odes by Horatius).

In retrospect, most of these problems were solved with time. I now understand that my time as the EIC provided me with invaluable experience, as I learned irreplaceable wisdom about life through the help of several mentors and many colleagues, in addition to my personal struggles. Above all, I am satisfied that the role of EIC of Ultrasonography kept me from being bored in my 50s. Of course, an EIC's work cannot be done alone, so I would like to thank my fellow editors, staff, and everyone else who supported me and the journal's work. For the past 9 years (June 2013 to the present), I have written annual Editorials published in the first issue of each year describing the details of the journal's development and expressing gratitude to the various contributors and stakeholders of the journal, so at this time, I would like to skip the details.

Now I introduce the new EIC who will take over starting with the next issue (Vol. 41, No. 3). Prof. Jung-Eun Cheon (ORCID ID: https://orcid.org/0000-0003-1479-2064) is an outstanding researcher and doctor in the field of pediatric radiology and has been helping me as a deputy editor of Ultrasonography for the past 7 years (Fig. 1). In particular, Prof. Cheon played a crucial role in ensuring the perfection of editing to the extent that Ultrasonography has not published a single erratum to date by minimizing the errors that can occur in the official publication of ePub papers. She also made major contributions to organizing the annual international scientific meeting program and successfully conducting the meeting as the chair of the Scientific Committee of the Korean Society of Ultrasound in Medicine (KSUM) for the past 3 years. I am fortunate and grateful to hand over the

\section{Jeong-Sik Yu, MD}

Department of Radiology, Gangnam Severance Hospital, Yonsei University College of Medicine, 211 Eonju-ro, Gangnam-gu, Seoul 06273, Korea Tel. +82-2-2019-3510, Fax.+82-2-3462-5472, E-mail: yjsrad97@yuhs.ac

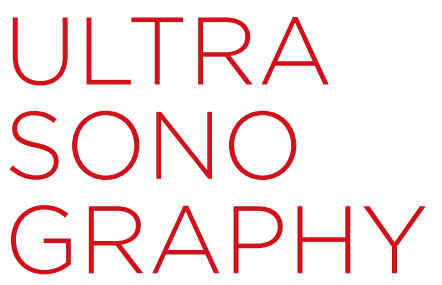

\section{EDITORIAL}

https://doi.org/10.14366/usg.22025 pISSN: 2288-5919 - elSSN: 2288-5943

Ultrasonography 2022;41:223-224

Received: February 18, 2022

Revised: February 27, 2022

Accepted: February 27, 2022

This is an Open Access article distributed under the terms of the Creative Commons Attribution NonCommercial License (http://creativecommons.org/ licenses/by-nc/4.0/) which permits unrestricted noncommercial use, distribution, and reproduction in any medium, provided the original work is properly cited.

Copyright (C) 2022 Korean Society of Ultrasound in Medicine (KSUM)

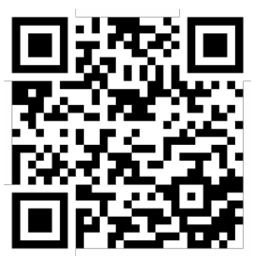

How to cite this article:

Yu JS. ULTRASONOGRAPHY: farewell and introduction of the new Editor-in-Chief. Ultrasonography. 2022 Apr;41(2):223-224. 


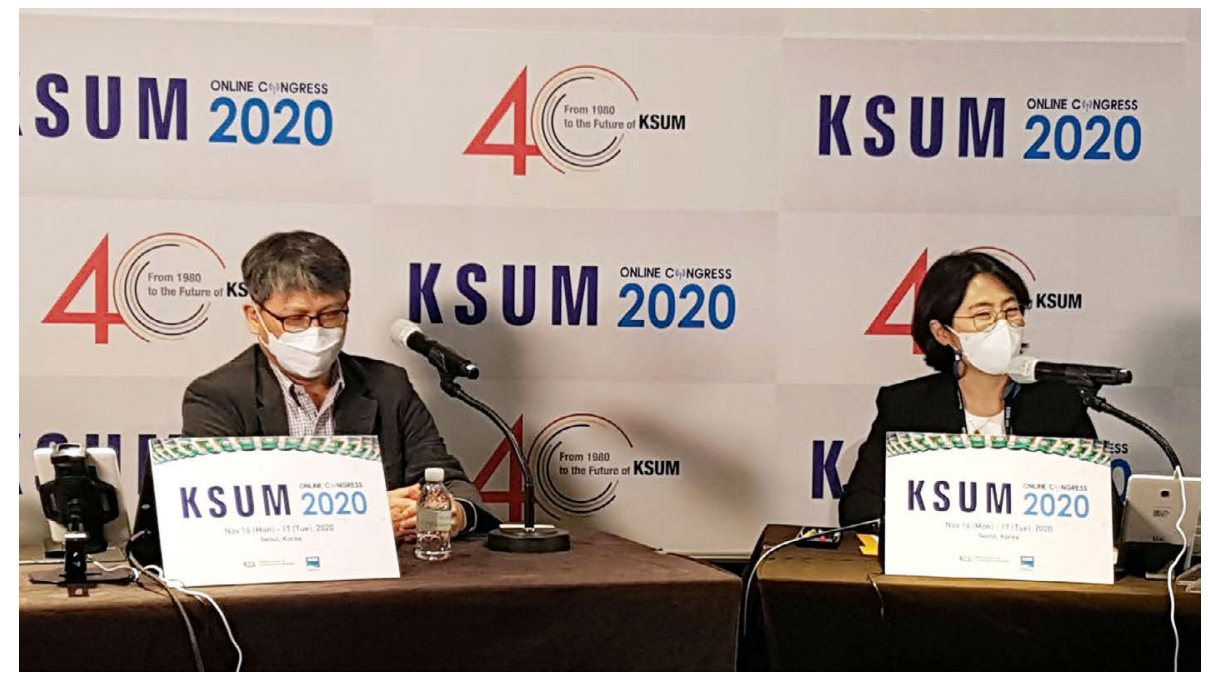

Fig. 1. Prof. Cheon (right) and I (left) at an editorial workshop held at the 2020 scientific meeting to commemorate the 40th anniversary of the Korean Society of Ultrasound in Medicine.

work to the right person who will carry out this role well, as the next

ORCID: Jeong-Sik Yu: https://orcid.org/0000-0002-8171-5838

EIC with deep experience and a new vision. 